ORIGINAL ARTICLE

\title{
Continuous positive airway pressure improves sleepiness but not calculated vascular risk in patients with minimally symptomatic obstructive sleep apnoea: the MOSAIC randomised controlled trial
}

\author{
Sonya Elizabeth Craig, ${ }^{1}$ Malcolm Kohler, ${ }^{2}$ Debby Nicoll, ${ }^{1}$ Daniel J Bratton, ${ }^{3}$ \\ Andrew Nunn, ${ }^{3}$ Robert Davies, ${ }^{1}$ John Stradling ${ }^{1,4}$
}

\begin{abstract}
- Additional supplementary appendix and table are published online only. To view this file please visit the journal online (http://dx.doi.org/10 1136/thoraxjnl-2012-202178).

${ }^{1} 0 x f o r d$ Centre for Respiratory Medicine, Churchill Hospital, Oxford, UK

${ }^{2}$ Sleep Disorders Centre and Pulmonary Division, University Hospital Zurich, Zurich,

Switzerland

${ }^{3}$ Medical Research Council Clinical Trials Unit, London, UK ${ }^{4}$ Oxford University and Oxford Biomedical Research Centre Churchill Hospital, Oxford, UK
\end{abstract}

\section{Correspondence to} Dr Sonya Elizabeth Craig, Oxford Centre for Respiratory Medicine, Churchill Hospital, Old Road, Headington, Oxford OX3 7LJ, UK;

sonya.craig@orh.nhs.uk

Professor Davies died during the early preparation stage of this paper.

Received 28 June 2012 Accepted 5 October 2012

\begin{abstract}
Background Continuous positive airway pressure (CPAP) for symptomatic obstructive sleep apnoea (OSA) improves sleepiness and reduces vascular risk, but such treatment for the more prevalent, minimally symptomatic disease is contentious.

Methods This multicentre, randomised controlled, parallel, hospital-based trial across the UK and Canada, recruited 391 patients with confirmed OSA (oxygen desaturation index $>7.5 / \mathrm{h}$ ) but insufficient symptoms to warrant CPAP therapy. Patients were randomised to 6 months of auto-adjusting CPAP therapy, or standard care. Coprimary endpoints were change in Epworth Sleepiness Score (ESS) and predicted 5-year mortality using a cardiovascular risk score (components: age, sex, height, systolic blood pressure, smoking, diabetes, cholesterol, creatinine, left ventricular hypertrophy, previous myocardial infarction or stroke). Secondary endpoints included some of the individual components of the vascular risk score, objectively measured sleepiness and self-assessed health status.
\end{abstract}

Results Of 391 patients randomised, 14 withdrew, 347 attended for their follow-up visit at 6 months within the predefined time window, of which 341 had complete ESS data (baseline mean 8.0, SD 4.3) and 310 had complete risk score data. $22 \%$ of patients in the CPAP group reported stopping treatment and overall median CPAP use was $2: 39 \mathrm{~h}$ per night. CPAP significantly improved subjective daytime sleepiness (adjusted treatment effect on ESS $-2.0(95 \% \mathrm{Cl}-2.6$ to -1.4$)$, $p<0.0001$ ), objectively measured sleepiness and selfassessed health status. CPAP did not improve the 5-year calculated vascular risk or any of its components.

Conclusions In patients with minimally symptomatic OSA, CPAP can reduce subjective and objective daytime sleepiness, and improve self-assessed health status, but does not appear to improve calculated vascular risk.

\section{INTRODUCTION}

Obstructive sleep apnoea (OSA) leads to recurrent hypoxic episodes, repeated arousals, surges in blood pressure (BP) and, in some patients, excessive daytime sleepiness and raised diurnal BP. Approximately $20-30 \%$ of the middle-aged population has some degree of OSA, most with few or no symptoms. ${ }^{12}$ Severity of sleepiness from OSA correlates poorly with sleep study severity of OSA. ${ }^{3}$ This is likely due to inter-individual variation in the degree of brain arousal from apnoeas, ${ }^{4}$ the effect these arousals have on daytime function ${ }^{5}$ and an individual's lifestyle. The UK National Institute for Health and Clinical Excellence (NICE) concluded that only two papers, with conflicting results, looked at the benefit of continuous positive airway pressure (CPAP) at low levels of OSA symptom severity. ${ }^{6-8}$ Thus one aim of the current study was to identify any symptomatic benefit from CPAP in sleep clinic patients with apparently minimal symptoms.

During each apnoea there are often recurrent hypoxic dips and surges in BP.9 These events may provoke sustained hypertension and several other potentially adverse cardiovascular consequences. ${ }^{10-16}$ While the acute effects of OSA on BP are abolished by $\mathrm{CPAP}^{9}$ any beneficial effects on sustained hypertension appear to be limited mainly to the more severe and symptomatic patients, with little benefit observed in non-sleepy patients in short-term randomised trials. ${ }^{6-8}$ Thus the second aim of this study was to assess the effect of 6 months of CPAP therapy on several potentially adverse vascular consequences, combined in an established calculated vascular risk algorithm in minimally symptomatic patients with OSA.

\section{METHODS \\ Study design}

The Multicentre Obstructive Sleep Apnoea Interventional Cardiovascular trial (MOSAIC) was a randomised, parallel, 6-month controlled trial that was conducted between May 2006 and February 2010. There were 10 recruiting centres in the UK and Canada, with Oxford as the coordinating centre. All centres are designated sleep units with facilities for diagnosis, treatment and follow-up of patients with OSA, and have healthcare professionals specifically trained in CPAP set-up and usage. The trial was approved by the ethics committees of all the centres (REC No: 05/ Q1604/159) and registered (ISRCTN 34164388).

\section{Patients}

Patients referred to sleep clinics, usually due to snoring, witnessed apnoeas or daytime sleepiness, 
were assessed for eligibility and a screening log was kept. All patients were diagnosed with OSA using overnight respiratory polygraphy as standard in the participating centres. Patients were eligible if they were aged between 45 and 75 years, had proven OSA on the diagnostic sleep study, with $>7.5$ per hour oxygen desaturations of $>4 \%$ (oxygen desaturation index, ODI), but had insufficient daytime symptoms associated with OSA to warrant CPAP therapy. This decision followed a detailed discussion between physician and patient about the evidence for possible benefits of CPAP versus the potentially lifelong nightly usage of a physical therapy. Thus patients with Epworth Sleepiness Scores (ESS) above the conventional upper normal limit (9) were included, when this was not accompanied by patient concerns. In addition, to ensure technical uniformity of the ODI across centres, a second domiciliary, overnight, pulse-oximetry recording (Konica-Minolta Inc, Osaka, Japan) was performed in all patients at baseline and at 6 months. This was used as the trial ODI value, which could therefore be different from the entry ODI. All patients who gave informed consent did so in accordance with Good Clinical Practice standards.

\section{Continuous positive airway pressure}

Patients assigned to CPAP were instructed in the use of an auto-adjusting CPAP machine (Autoset S8, ResMed, Abingdon, UK). Induction was by trained staff who were not involved in outcome assessments or data analysis. Humidification and interface choices were made on an individual basis. All patients had one or more follow-up visits to download compliance data, check for residual apnoea/hypopnoeas and mask leakage, and to make any necessary adjustments. There were routine telephone calls at 2 and 4 months, and telephone advice and replacement parts if requested by the patient.

\section{Standard care}

The standard care (SC) group had an identical planned visit schedule to the CPAP group. Both groups were asked to continue on their normal medication and not given any specific advice regarding diet and exercise.

\section{Outcomes}

The joint primary outcomes at 6 months (predefined time window 5-8 months) were change in ESS, and change in a composite vascular risk endpoint, the 5-year risk of a fatal cardiovascular event calculated using a cardiovascular risk score. Secondary outcomes at 6 months were change in objective sleepiness, selfassessed health status, BP, lipids, glucose metabolism, obesity measures, vascular events and sleep apnoea severity (ODI).

\section{Assessments of sleepiness}

Subjective sleepiness was determined using the ESS, ${ }^{17}$ which assesses the tendency to fall asleep during eight typical daytime scenarios. Objective sleepiness was assessed using one Oxford Sleep Resistance (OSLER) test administered at the same time of day (Stowood Scientific Instruments Oxford, UK), a sleep resistance challenge which tests the ability to stay awake for $40 \mathrm{~min}$ in a quiet, darkened room. ${ }^{18} 19$

\section{Self-assessed health status}

The Medical Outcome Study, the 36-item Short-Form health survey (SF-36) ${ }^{20}$ the Calgary Sleep Apnoea Quality-of-Life Index (SAOLI) ${ }^{21}$ and the two-part Euroqol (EQ-5D) questionnaires $^{22}$ were administered by trial staff and are described in the online supplementary appendix.
BP measurements and blood tests are also given in the online supplementary appendix.

\section{Cardiovascular risk score}

To avoid the problem of multiple comparisons, a calculated vascular risk score was used as a composite endpoint, thus allowing the inclusion of relevant factors with their correct relative weightings (only some of which could potentially be affected by OSA or its treatment). The algorithm proposed by Pocock et $a l^{23}$ is similar to the Framingham risk score but estimates the probability of a fatal cardiovascular event within 5 years from 11 factors: age (at baseline), sex, height, systolic BP (median of a 7-day period), total cholesterol, creatinine, cigarette smoking (current smoker if smoked in the previous month), diabetes (either on treatment, previously diagnosed and in general practice records, or fasting glucose $\geq 7 \mathrm{mmol} /$ litre and haemoglobin A1c (HbA1c) $>6.5 \%$ ), left ventricular hypertrophy (Sokolov-Lyon method on ECG), history of cerebrovascular incident and/or myocardial infarction (from general practice records and verified from hospital case records if equivocal). Although some of these factors clearly could not change during follow-up (thus representing a 'fixed offset'), their inclusion is necessary to derive a valid single risk score with the correct weightings.

Sample size calculation, randomisation data and statistical methods are given in the online supplementary appendix.

\section{RESULTS \\ Flow diagram of trial allocation, implementation of intervention and baseline data}

Figure 1 shows the trial profile. The trial was stopped nine patients short of the target of 400 because the number not attending for follow-up (4\%) was lower than predicted $(10 \%)$. Baseline data by group assignment are shown in table 1, and the baseline distribution of ESS scores by group assignment is shown in the online supplementary appendix (figure a).

\section{Primary outcomes}

Table 2 shows a summary of the adjusted treatment effects for the primary outcomes, including the results of the imputation and sensitivity analyses (further described in the online supplementary appendix). CPAP improved subjective sleepiness by a two-point reduction in the ESS scale compared with the SC group $(95 \% \mathrm{CI}-2.6$ to $-1.4 ; \mathrm{p}<0.0001)$. There was a small, clinically insignificant, absolute increase of $0.1 \%$ in the 5 -year risk of a fatal vascular event in the CPAP arm, relative to SC ( $95 \%$ CI $0.0 \%$ to $+0.2 \%$; $=0.070)$. The analyses of the components of the risk score in patients included in the primary risk score analysis are shown in table 3.

\section{Secondary outcomes}

Objective sleepiness

The proportion of patients falling asleep during the $40 \mathrm{~min}$ OSLER test was similar in the two groups at baseline $39 \%$ and $35 \%$ in the SC and CPAP group, respectively). At 6 months, the odds of falling asleep during the OSLER test were 44\% lower in the CPAP treatment group compared with SC $(95 \% \mathrm{CI}-1$ to $-68 \%$ ), $p=0.045$ (logistic regression). A 'time to event' (falling asleep) Kaplan-Meier plot of these data is shown in figure 2.

\section{Indices of self-assessed health status}

Most components of the SF-36 (except bodily pain, mental health and role physical) showed evidence of improvement following CPAP (tables 4 and 5, figure 3). The largest treatment effect was in energy/vitality, +6.6 (95\% CI +3.1 to +10.1), 


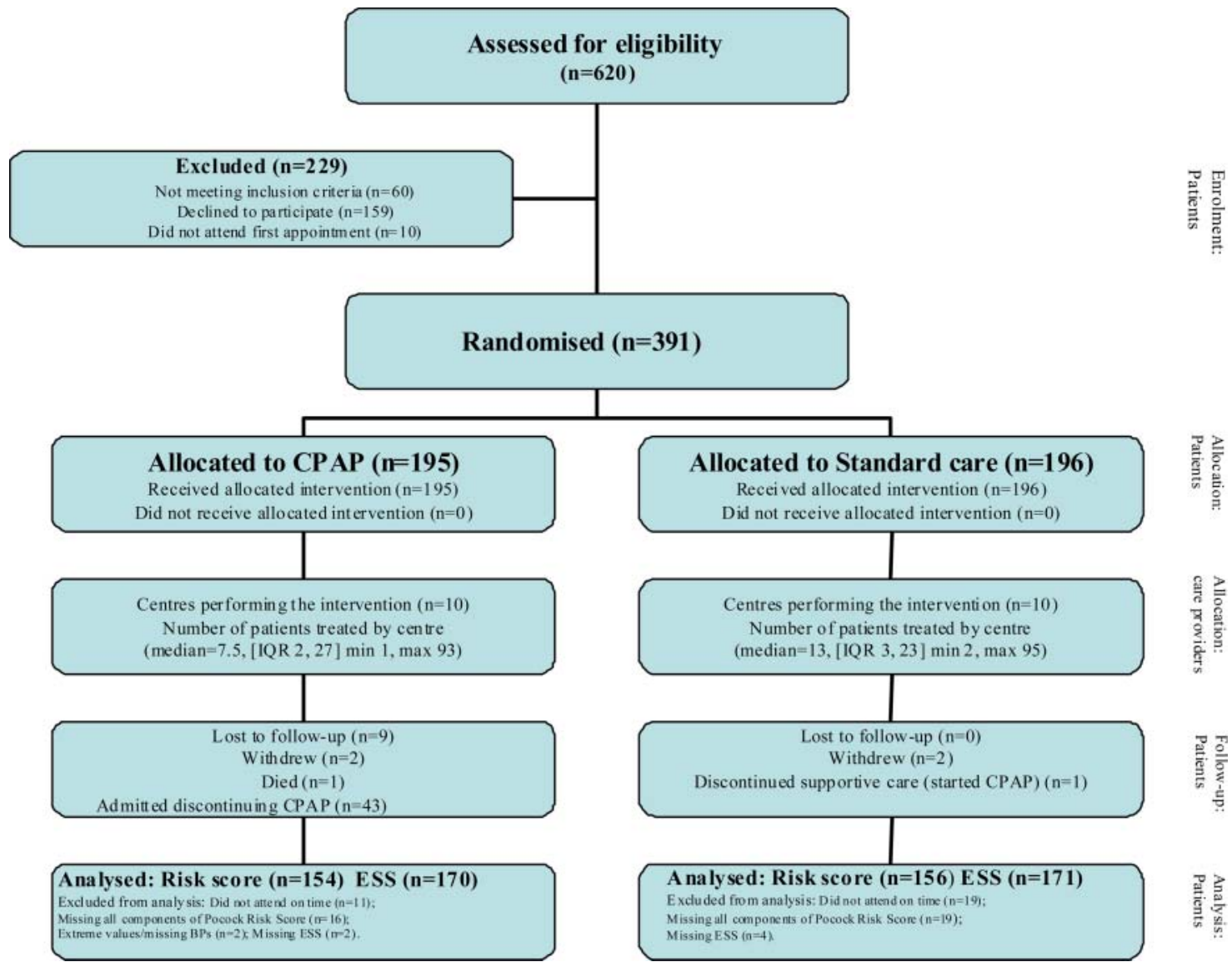

Figure 1 Flow diagram showing the trial allocation. BP, blood pressure; CPAP, continuous positive airway pressure; ESS, Epworth Sleepiness Score. This figure is only reproduced in colour in the online version.

$\mathrm{p}<0.0001$. The mental component score improved by 2.6 points $(95 \% \mathrm{CI}+0.9$ to +4.2$), \mathrm{p}=0.003$. The SAOLI also showed a statistically significant improvement, but the small improvement in the Euroqol was not statistically significant (see online supplementary appendix tables a and b).

\section{Other metabolic and vascular outcomes \\ CPAP usage}

Forty-three (22\%) of the 195 patients randomised to CPAP reported stopping treatment during follow-up (see online supplementary appendix, tables $\mathrm{c}$ and $\mathrm{d}$ ). Of the 172 patients on CPAP who attended their 6-month visit 'on time' (predefined time window 5-8 months), 150 (87\%) had compliance data at 6 months. Median CPAP usage was $2: 39$ h/night (IOR $0: 36$ to $4: 59$ ), with compliance in non-users with missing data set to zero. Including all the patients on CPAP in the analysis did not substantially alter this result (median $2: 27 \mathrm{~h} /$ night (IOR $0: 28$ to $4: 55)$ ). Age, sex, study centre and baseline ODI, ESS, body mass index, neck circumference and OSLER result were not predictive of CPAP compliance. Following the end of the 6-month trial, $71 \%$ of patients randomised to CPAP expressed a wish to continue CPAP.

\section{Effect of CPAP usage on outcomes}

Figure $4 \mathrm{~A}$ shows the effect of $<4 \mathrm{~h} /$ night and $\geq 4 \mathrm{~h} /$ night of CPAP usage on change in ESS compared with SC. There was a statistically significant improvement in ESS with greater CPAP compliance $(p=0.0001)$. The effect of CPAP usage on self-assessed health status outcomes are detailed in the online supplementary appendix (figure b). Figure $4 \mathrm{~B}$ shows the effect of CPAP usage on change in 5-year vascular risk compared with SC. There is no evidence to suggest that good compliance ( $\geq 4 \mathrm{~h} /$ night) improved vascular risk compared with poor compliance $(<4 \mathrm{~h} /$ night, $\mathrm{p}=0.49$ ). The effect of CPAP usage on systolic $\mathrm{BP}$ and $\mathrm{HbA1c}$ are detailed in the online supplementary appendix (figure c). The effect of CPAP usage on ODI is also shown in the online supplementary appendix (table $\mathrm{c}$ and figure g).

Association of age, sex, ODI, baseline ESS and hypertensive status with outcomes

The effect of CPAP therapy on ESS was largely independent of baseline ODI, age or sex (figure 5). There was some evidence that patients with ESS scores in the two quartiles above the median at baseline benefitted more than those below the median. However, there was still a significant treatment effect even in those in the lowest ESS quartile at baseline. The effect of CPAP therapy on 5-year vascular risk was independent of baseline ESS, ODI, age, sex and hypertensive status (figure 5). The effect of the above factors on systolic BP is detailed in the online supplementary appendix (figure $\mathrm{d}$ ). The association between baseline ESS and change in diastolic BP and cholesterol are detailed in the online supplementary appendix (figures $e$ and $f$ ).

\section{DISCUSSION}

This study has shown that in minimally symptomatic patients with OSA, 6 months of CPAP therapy improves daytime 
Table 1 Baseline characteristics and minimisation variables in all MOSAIC patients

\begin{tabular}{|c|c|c|}
\hline & $\begin{array}{l}\text { Standard care } \\
(N=196)\end{array}$ & $\begin{array}{l}\text { CPAP } \\
(N=195)\end{array}$ \\
\hline Epworth Sleepiness Score & $8.0(4.2)$ & $7.9(4.4)$ \\
\hline Vascular risk score & $35.7(7.6)$ & $35.5(7.7)$ \\
\hline \multicolumn{3}{|l|}{ Vascular risk score components } \\
\hline Sex (men) & $152(77.6 \%)$ & $153(78.5 \%)$ \\
\hline Age (years) & $57.6(7.5)$ & $57.9(7.2)$ \\
\hline Height (cm) & $174.8(8.8)$ & $174.0(9.1)$ \\
\hline Total cholesterol (mmol/l) & $5.2(1.2)$ & $5.3(1.2)$ \\
\hline Systolic BP (mm Hg) & $129.6(13.6)$ & $129.7(11.6)$ \\
\hline Creatinine $(\mu \mathrm{mol} /$ litre $)$ & $95.5(18.8)$ & $92.0(14.9)$ \\
\hline Left ventricular hypertrophy & $3(1.6 \%)$ & $2(1.1 \%)$ \\
\hline Previous myocardial infarction & $14(7.1 \%)$ & $9(4.6 \%)$ \\
\hline Previous stroke & $1(0.5 \%)$ & $4(2.1 \%)$ \\
\hline Diabetic & $40(20.4 \%)$ & $23(11.8 \%)$ \\
\hline \multicolumn{3}{|l|}{ Smoking status } \\
\hline Current smoker & $28(14.3 \%)$ & $17(8.7 \%)$ \\
\hline Ex-smoker & $97(49.5 \%)$ & $102(52.3 \%)$ \\
\hline Hypertensive & $149(76.0 \%)$ & $151(77.4 \%)$ \\
\hline $\begin{array}{l}\text { Oxygen desaturation index (> }>4 \% \\
\text { dips/h) }\end{array}$ & $9.4(5.2,15.0)$ & $10.2(4.7,17.5)$ \\
\hline Resting $\mathrm{O}_{2}$ saturation $(\%)$ & $96.0(1.4)$ & $96.0(1.3)$ \\
\hline OSLER (min) & $40 \cdot 0(25 \cdot 8,40 \cdot 0)$ & $40.0(27 \cdot 0,40 \cdot 0$ \\
\hline Waist circumference (cm) & $109.4(12.9)$ & $108.1(12.6)$ \\
\hline BMI $\left(\mathrm{kg} / \mathrm{m}^{2}\right)$ & $32.5(5.6)$ & $32.2(5.6)$ \\
\hline Neck circumference (cm) & $43.0(4.0)$ & $42.5(3.9)$ \\
\hline Diastolic BP (mm Hg) & $81.3(8.0)$ & $81.3(7.7)$ \\
\hline
\end{tabular}

Data are presented as mean (SD), median (25th, 75 th percentiles) or number of patients (\%)

$\mathrm{BMI}$, body mass index; $\mathrm{BP}$, blood pressure; CPAP, continuous positive airway pressure; MOSAIC, Multicentre Obstructive Sleep Apnoea Interventional Cardiovascular trial; OSLER, Oxford Sleep Resistance test.

Table 2 Primary outcome results. Adjusted treatment effects (CPAP change minus standard care change) for ESS, and percentage risk of fatal cardiovascular event within 5 years

\begin{tabular}{lccc}
\hline & $\begin{array}{l}\text { Standard care/ } \\
\text { CPAP (N) }\end{array}$ & $\begin{array}{l}\text { Adjusted treatment } \\
\text { effect (95\% CI) }\end{array}$ & p Value \\
\hline ESS & $\begin{array}{l}\text { 171/170 } \\
\text { 5-year risk of fatal vascular event (\%) }\end{array}$ & $-2.0(-2.6$ to -1.4$)$ & $<0.0001$ \\
$\quad \begin{array}{l}\text { Primary analysis } \\
\quad\end{array}$ & $156 / 154$ & $+0.1(0.0$ to +0.2$)$ & 0.070 \\
$\begin{array}{l}\text { Sensitivity analysis } \\
\text { (ignoring smoking changes) } \\
\text { Imputation analysis }\end{array}$ & $156 / 154$ & $+0.1(0.0$ to +0.1$)$ & 0.19 \\
\hline CPAP, continuous positive airway pressure; ESS, Epworth Sleepiness Score. &
\end{tabular}

sleepiness and self-assessed health status, but does not improve the calculated 5-year risk of a fatal cardiovascular event, or any of its component parts.

The individuals in this study were less sleepy than in the majority of previous randomised controlled studies on CPAP. In two of our previous comparable trials the mean baseline ESS of 16 , and the median baseline OSLER of $21 \mathrm{~min}$, compares to about 8 and 40 min, respectively. ${ }^{24} 25$ The ESS improvement was seen across almost the whole spectrum of baseline ESS severity. Compared with SC, the number needed to treat for at least a two-point ESS improvement is about four (online supplementary appendix, table e). The fall in ESS of two points, relative to control, compares to a fall of about five points observed in one of our previous studies mentioned above. ${ }^{24}$ Because the ESS scale is an ordinal, rather than a linear, measure of sleepiness, it is difficult to compare changes at different points across the spectrum. However, in the NICE economic model, ${ }^{26}$ a drop of 2.3 in ESS in patients treated with CPAP incurred a cost of $£ 9331$ and was considered economically viable. This drop of two in ESS would be expected in theory to improve work productivity by about $2 \%^{27}$ and reduce sleep-related road accident rates by about $9 \%,{ }^{28}$ further adding to the cost efficacy of treatment.

This effect of CPAP on sleepiness was also observed almost equally across the whole ODI spectrum, confirming previous findings that the correlation between symptoms and apnoeahypopnoea index (AHI), or ODI, is very poor. Nearly a quarter of patients started on CPAP in the current study admitted stopping therapy as they did not perceive benefits to outweigh inconvenience. However, $71 \%$ stated at the 6-month appointment that they wished to continue CPAP long term. This is similar to long-term CPAP take-up rates for patients with moderate OSA in many centres, including our own. ${ }^{29} 30$ From the baseline data we collected, there were no clear ways to predict in advance which individuals will benefit from treatment (figure 5).

We have also shown that self-assessed health status, as measured by SF-36 and SAOLI, improves with CPAP in patients with minimally symptomatic OSA. A previous randomised controlled trial of self-assessed health status in severely sleepy subjects with OSA showed treatment effects of 0.9 in the SAQLI, ${ }^{31}$ and 14.5 in the Energy/Vitality component of SF-36, compared with the current trial of 0.6 and 6.6, respectively. This suggests that CPAP therapy in patients with minimally symptomatic OSA produces an improvement in self-assessed health status of $45-70 \%$ of that seen in severely sleepy patients.

Despite the clear symptomatic response to CPAP there was, if anything, weak evidence that vascular risk slightly worsened

Table 3 Baseline and follow-up means (SD) and adjusted treatment effects for the components of the vascular risk score

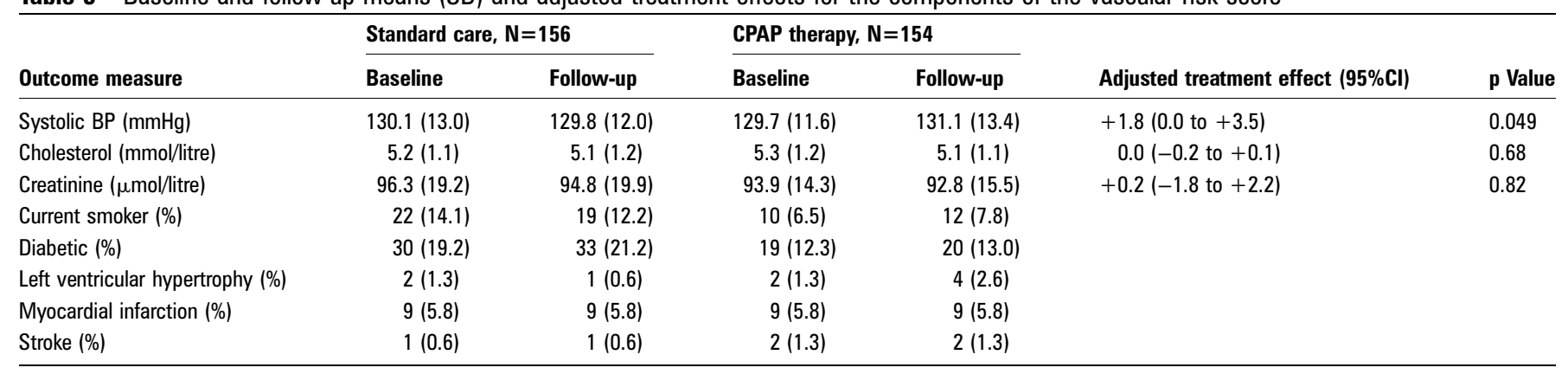

$\mathrm{BP}$, blood pressure; CPAP, continuous positive airway pressure. 


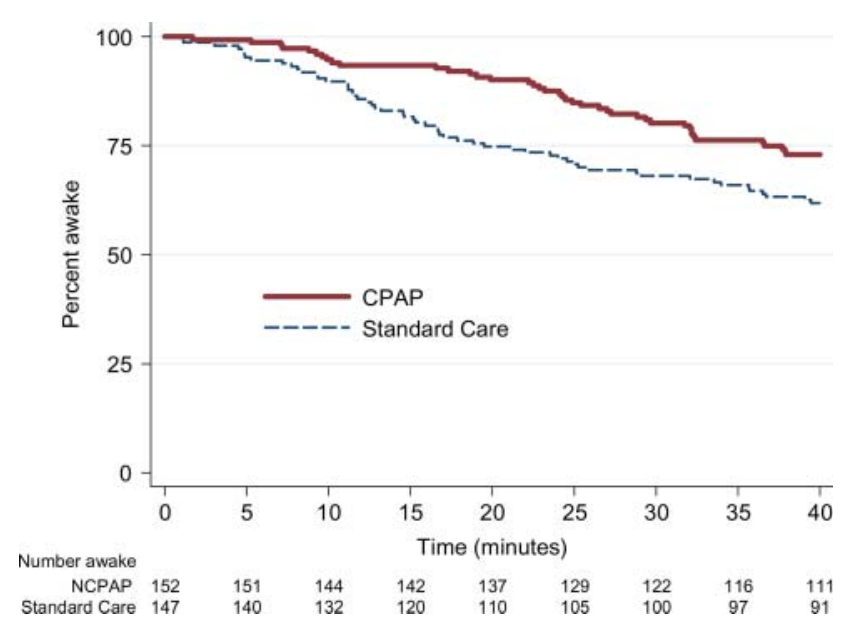

Figure 2 Kaplan-Meier plot showing the percent (and number) of subjects remaining awake during the Oxford Sleep Resistance (OSLER) test, for the standard care group and continuous positive airway pressure (CPAP) group at the 6-month follow-up visit.This figure is only reproduced in colour in the online version.

compared with SC, although the effect was clinically insignificant. This unimportant adverse effect was largely explained by small statistically non-significant differential changes in both smoking status and BP (and its medication) over the 6 months (table 2). Change in vascular risk did not seem to be related to initial OSA severity, or CPAP compliance, implying that we probably did not miss an effect, simply because overall compliance with CPAP was low. However, in the subgroup of patients with higher baseline ESS values ( $>11)$, there was a trend towards an improvement in vascular risk with CPAP (figure 5). Similarly systolic and diastolic BP, and cholesterol did fall in the CPAP arm relative to the SC arm in patients with higher ESS $(>11)$, although these interactions were not statistically significant (online supplementary appendix, figures $d-f$ ). The drop in cholesterol of $0.30 \mathrm{mmol} /$ litre in our most sleepy patients was similar to the findings of a previous study showing a fall in cholesterol of $0.28 \mathrm{mmol} /$ litre in a more severely affected and sleepy population (mean ESS 16) treated for 1 month with CPAP. ${ }^{11}$ This suggests that patients with greater sleepiness benefit more than non-sleepy patients and supports previous findings. ${ }^{7} 825$ A randomised controlled 12-month study by Barbe et $a l^{32}$ in a hypertensive non-sleepy population showed a small reduction in systolic and diastolic BP (1.9 and $2.2 \mathrm{~mm} \mathrm{Hg}, p=0.07$ and $p=0.0008$, respectively), but a larger effect ( 3.7 and $3.5 \mathrm{~mm} \mathrm{Hg}, \mathrm{p}=0.007$ and $\mathrm{p}=0.0001$, respectively) in patients with the highest CPAP compliance $(>5.6 \mathrm{~h} /$ night) who also had the largest improvement in sleepiness. More recently, the same group ${ }^{33}$ studied non-sleepy patients without prior cardiovascular events (some with hypertension)

Table 4 SF-36 questionnaire

\begin{tabular}{lll}
\hline Energy/vitality & Standard care, $\mathbf{N = 1 6 8}$ & $\begin{array}{l}\text { CPAP, } \\
\mathbf{N}=171\end{array}$ \\
\hline Baseline mean score (SD) & $49.7(23.7)$ & $49.8(22.4)$ \\
6-month mean score (SD) & $53.9(22.5)$ & $60.6(20.9)$ \\
Mean change (SE) & $+4.2(1.4)$ & $+10.8(1.3)$ \\
Adjusted treatment effect (95\% Cl), & $+6.6(+3.1$ to +10.1$)$, & \\
p value & $\mathrm{p}<0.0001$ & \\
\hline
\end{tabular}

Mean baseline and 6-month energy/vitality scores with adjusted treatment effect. An increase in the energy and vitality subscore indicates an improvement in health status. CPAP, continuous positive airway pressure; SF-36, 36-item Short-Form health survey.
Table 5 SF-36 questionnaire

\begin{tabular}{lll}
\hline Mental component score & Standard care, N=158 & CPAP, N=165 \\
\hline Baseline mean score (SD) & $46.6(11.3)$ & $48.2(10.4)$ \\
6-month mean score (SD) & $48.5(11.0)$ & $52.0(9.8)$ \\
Mean change (SE) & $+1.9(0.7)$ & $+3.8(0.6)$ \\
Adjusted treatment effect & $+2.6(+0.9$ to +4.2$)$, & \\
(95\% Cl), p value & $\mathrm{p}=0.003$ & \\
\hline
\end{tabular}

Mean baseline and 6-month mental component scores with adjusted treatment effect. An increase in mental component score indicates an improvement in health status. CPAP, continuous positive airway pressure.

over a median of 4 years. Although there was no significant overall reduction in new events (predominantly new onset hypertension) in the CPAP group, the subgroup of patients prepared to use CPAP for $>4 \mathrm{~h} /$ night did experience a reduction in vascular events. Interestingly, in both these trials the baseline AHI of the study population was higher (mean 45 and 39) than the ODI in our study (median 10), and thus these patients probably had worse OSA.

As no sham CPAP was used in our control group, our results might merely be due to a placebo effect of CPAP, observed in previous short trials. ${ }^{24}{ }^{25}$ However, as this was a 6-month trial, the placebo effect is likely to have diminished with time. In addition, previous studies employing sham CPAP did not generate placebo effects with the OSLER test; ${ }^{24}$ yet we have demonstrated a significant treatment effect on this objective measure of sleepiness.

We adopted a clinical approach to setting up CPAP therapy, without overnight CPAP titration, which has become standard in many UK and European based sleep centres. ${ }^{34}$ We obtained relatively low CPAP compliance, probably representing the likely usage when such non-sleepy patients are offered CPAP, which may have lessened the chance of demonstrating an effect on vascular risk, although there was no benefit in the sizeable subgroup of higher compliers. Similar to the current trial, CPAP compliance has been reported to be relatively low $(2.9 \mathrm{~h} / \mathrm{night})$ in a study using overnight CPAP titration to establish an optimal pressure to abolish breathing irregularities in patients with mild OSA. ${ }^{35}$ However, the Spanish group has managed to achieve higher compliance levels in their trials on non-sleepy patients (defined as ESS $<10$ ). ${ }^{32} 33$

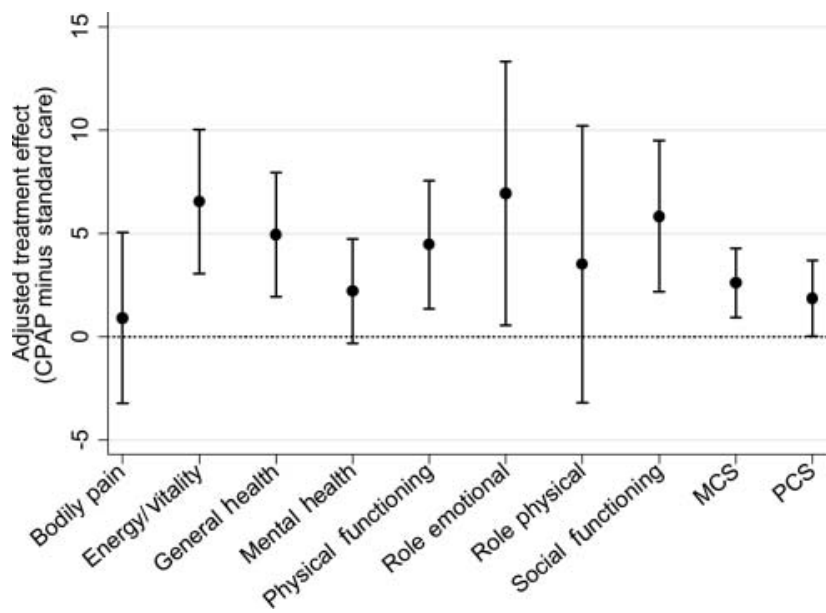

Figure 3 36-item Short-Form health survey (SF-36). Adjusted treatment effects and their $95 \%$ Cls on the mental component score (MCS), physical component score (PCS) and their eight individual components. Higher scores indicate improved self-assessed health status. CPAP, continuous positive airway pressure. 
Figure 4 Forest plots showing the adjusted treatment effects by continuous positive airway pressure (CPAP) compliance $(<4 \mathrm{~h} /$ night and $\geq 4 \mathrm{~h} /$ night), with tests for interactions, on (A) Epworth Sleepiness Score (ESS) and (B) vascular risk (\%).

A

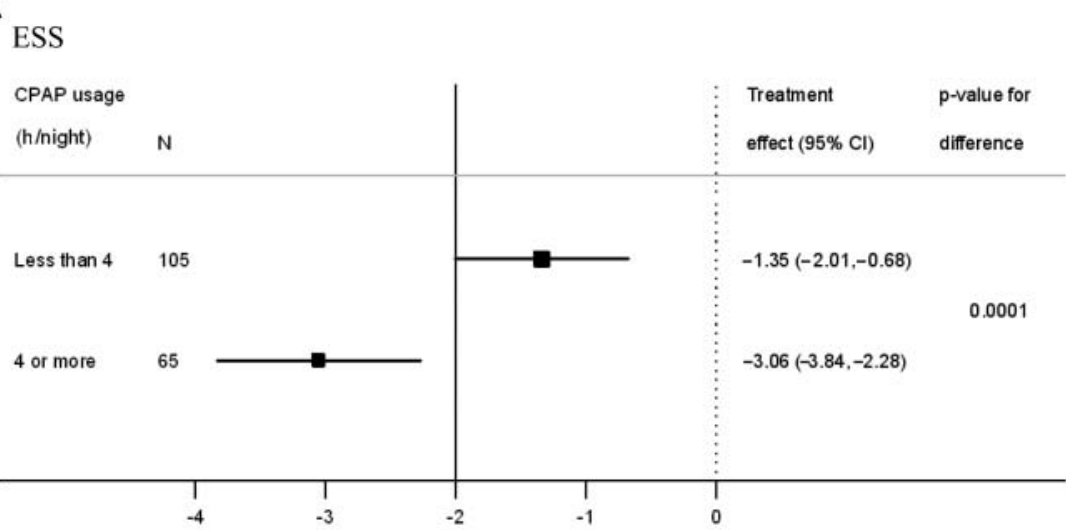

B

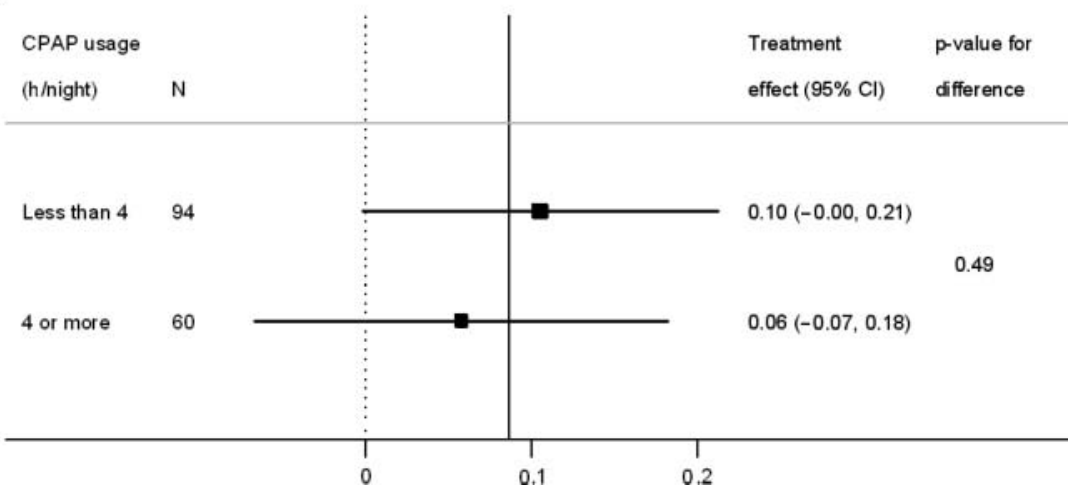

It may be that the markers of cardiovascular risk included in the risk score are either too insensitive or unlikely to change in a 6-month period, and other markers such as endothelial function, sympathetic activity levels or circulating inflammatory markers may more sensitively reflect any risk reduction. However, short trials of 1-month duration in more severely affected patients have shown clear reductions in $\mathrm{BP}^{25}$
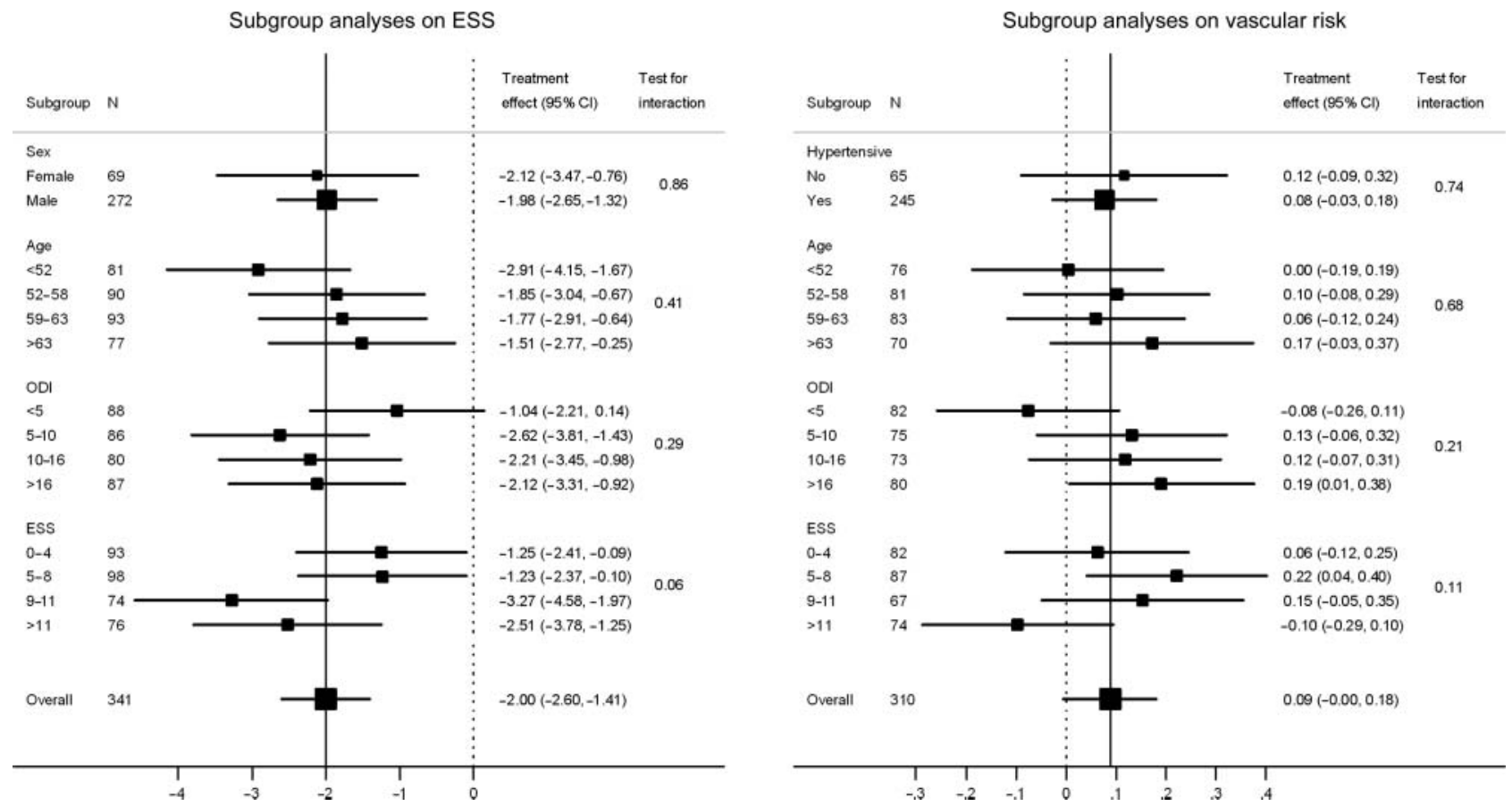

Figure 5 Forest plots showing the adjusted treatment effects, with tests for interaction, on Epworth Sleepiness Score (ESS) (left panel, by sex and quartiles of age, baseline oxygen desaturation index (ODI) and baseline ESS), and on vascular risk (\%) (right panel, by baseline hypertensive status and quartiles of age, baseline ODI, baseline ESS). 
In conclusion, our findings show that even when there is little enthusiasm for CPAP by patient and physician, because of an apparent paucity of symptoms, nearly half of patients on CPAP experienced at least a two-point improvement in ESS. This positive treatment effect extends further down the spectrum of OSA symptom severity than was previously thought, but it is difficult to predict, at an individual level, which patients will benefit. However, this positive treatment effect on symptoms was not accompanied by a reduction in calculated vascular risk or BP. Thus CPAP should be offered to patients with OSA, despite minimal daytime symptoms, on a trial basis, but with the expectation that some will decide that the benefits do not justify the inconvenience and thus will return their equipment. Because this study was carried out in a general sleep clinic setting, it is therefore only applicable to mainstream sleep practice; the sleepiness and self-assessed health status benefits should not be extrapolated to subjects with undiagnosed OSA in the general population who have not had cause to present to a sleep clinic.

Contributors The authors fulfilled the criteria for authorship, had full access to all data in the study, and had final responsibility for the decision to submit for publication.

Funding The British Heart Foundation — unrestricted project grant, Oxford Health Services Research Committee paid for research salaries. ResMed UK made an unrestricted charitable donation to support research work in the Oxford Sleep Unit in 1998 and 2006, and supplied the CPAP machines for this trial. We would like to acknowledge the support of the NIHR Biomedical Research Centre Oxford.

\section{Competing interest None.}

Provenance and peer review Not commissioned; externally peer reviewed.

\section{REFERENCES}

1. Young T, Shahar E, Nieto FJ, et al. Predictors of sleep-disordered breathing in community-dwelling adults: the Sleep Heart Health Study. Arch Intern Med 2002;162:893-900

2. Young T, Skatrud J, Peppard PE. Risk factors for obstructive sleep apnea in adults. JAMA 2004;291:2013-16.

3. Martin SE, Engleman HM, Kingshott RN, et al. Microarousals in patients with sleep apnoea/hypopnoea syndrome. J Sleep Res 1997;6:276-80.

4. Rees K, Spence DPS, Earis JE, et al. Arousal responses from apneic events during non rapid-eye-movement sleep. Am J Respir Crit Care Med 1995;152:1016-21.

5. Durmer JS, Dinges DF. Neurocognitive consequences of sleep deprivation. Semin Neurol 2005;25:117-29.

6. McDaid C, Duree KH, Griffin SC, et al. A systematic review of continuous positive airway pressure for obstructive sleep apnoea-hypopnoea syndrome. Sleep Med Rev 2009;13:427-36

7. Barbe F, Mayoralas LR, Duran J, et al. Treatment with continuous positive airway pressure is not effective in patients with sleep apnea but no daytime sleepiness. A randomized, controlled trial. Ann Intern Med 2001;134:1015-23.

8. Robinson GV, Smith DM, Langford BA, et al. Continuous positive airway pressure does not reduce blood pressure in nonsleepy hypertensive OSA patients. Eur Respir J 2006;27:1229-35.

9. Ali NJ, Davies RJO, Fleetham JA, et al. The acute effects of continuous positive airway pressure and oxygen administration on blood pressure during obstructive sleep apnea. Chest 1992;101:1526-32.

10. Lovett JK, Rothwell PM. Site of carotid plaque ulceration in relation to direction of blood flow: an angiographic and pathological study. Cerebrovasc Dis 2003;16:369-75.

11. Robinson GV, Pepperell JC, Segal HC, et al. Circulating cardiovascular risk factors in obstructive sleep apnoea: data from randomised controlled trials. Thorax 2004;59:777-82.
12. Lavie L. Obstructive sleep apnoea syndrome - an oxidative stress disorder. Sleep Med Rev 2003; 7:35-51

13. Alonso-Fernandez A, Garcia-Rio F, Arias MA, et al. Effects of CPAP on oxidative stress and nitrate efficiency in sleep apnoea: a randomised trial. Thorax 2009;64:581-6.

14. Kohler M, Pepperell JC, Casadei B, et al. CPAP and measures of cardiovascular risk in males with OSAS. Eur Respir J 2008;32:1488-96.

15. Punjabi NM, Shahar E, Redline S, et al. Sleep-disordered breathing, glucose intolerance, and insulin resistance: the Sleep Heart Health Study. Am J Epidemiol 2004; 160:521-30.

16. Sanders $\mathbf{M H}$, Givelber R. Sleep disordered breathing may not be an independent risk factor for diabetes, but diabetes may contribute to the occurrence of periodic breathing in sleep. Sleep Med 2003;4:349-50.

17. Johns MW. A new method for measuring daytime sleepiness: the Epworth Sleepiness Scale. Sleep 1991;14:540-5.

18. Mazza S, Pepin JL, Naegele B, et al. Most obstructive sleep apnoea patients exhibit vigilance and attention deficits on an extended battery of tests. Eur Respir J 2005:25:75-80.

19. Bennett LS, Stradling JR, Davies RJO. A behavioural test to assess daytime sleepiness in obstructive sleep apnoea. J Sleep Res 1997;6:142-5.

20. Ware JE Jr, Sherbourne CD. The MOS 36-item Short-Form health survey (SF-36). I. Conceptual framework and item selection. Med Care 1992;30:473-83.

21. Flemons WW, Reimer MA. Development of a disease-specific health-related quality of life questionnaire for sleep apnea. Am J Respir Crit Care Med 1998;158:494-503.

22. Euroquol Group. Euroquol-A new facility for the measurement of health-related quality of life. Health Policy 1990;16:199-208.

23. Pocock SJ, McCormack V, Gueyffier F, et al. A score for predicting risk of death from cardiovascular disease in adults with raised blood pressure, based on individual patient data from randomised controlled trials. BMJ 2001;323:75-81.

24. Jenkinson C, Davies RJ, Mullins R, et al. Comparison of therapeutic and subtherapeutic nasal continuous positive airway pressure for obstructive sleep apnoea: a randomised prospective parallel trial. Lancet 1999;353:2100-5.

25. Pepperell JC, Ramdassingh-Dow S, Crosthwaite N, et al. Ambulatory blood pressure after therapeutic and subtherapeutic nasal continuous positive airway pressure for obstructive sleep apnoea: a randomised parallel trial. Lancet 2002;359:204-10.

26. Weatherly HL, Griffin SC, Mc DC, et al. An economic analysis of continuous positive airway pressure for the treatment of obstructive sleep apnea-hypopnea syndrome. Int J Technol Assess Health Care 2009;25:26-34.

27. Mulgrew AT, Ryan CF, Fleetham JA, et al. The impact of obstructive sleep apnea and daytime sleepiness on work limitation. Sleep Med 2007;9:42-53.

28. Powell NB, Schechtman KB, Riley RW, et al. Sleepy driver near-misses may predict accident risks. Sleep 2007;30:331-42.

29. Kohler M, Smith D, Tippett $\mathrm{V}$, et al. Predictors of long-term compliance with continuous positive airway pressure. Thorax 2010;65:829-32.

30. McArdle N, Devereux G, Heidarnejad H, et al. Long-term use of CPAP therapy for sleep apnea/hypopnea syndrome. Am J Respir Crit Care Med 1999;159 1108-14.

31. Siccoli MM, Pepperell JC, Kohler M, et al. Effects of continuous positive airway pressure on quality of life in patients with moderate to severe obstructive sleep apnea: data from a randomized controlled trial. Sleep 2008:31:1551-8.

32. Barbe F, Duran-Cantolla J, Capote F, et al. Long-term effect of continuous positive airway pressure in hypertensive patients with sleep apnea. Am J Respir Crit Care Med 2010;181:718-26.

33. Barbe F, Duran-Cantolla J, Sanchez-de-la-Torre M, et al. Effect of continuous positive airway pressure on the incidence of hypertension and cardiovascular events in nonsleepy patients with obstructive sleep apnea: a randomized controlled trial. JAMA 2012;307:2161-68.

34. Senn 0, Brack T, Matthews F, et al. Randomized short-term trial of two autoCPAP devices versus fixed continuous positive airway pressure for the treatment of sleep apnea. Am J Respir Crit Care Med 2003;168:1506-11.

35. Engleman HM, Kingshott RN, Wraith PK, et al. Randomized placebo-controlled crossover trial of continuous positive airway pressure for mild sleep apnea/hypopnea syndrome. Am J Respir Crit Care Med 1999:159:461-7. 


\section{Correction}

Craig SE, Kohler M, Nicoll D, et al. Continuous positive airway pressure improves sleepiness but not calculated vascular risk in patients with minimally symptomatic obstructive sleep apnoea: the MOSAIC randomised controlled trial. Thorax 2012;67:1090-1096. doi:10.1136/ thoraxjnl-2012-202178.

The acknowledgement section for this article should read:

Principal investigators Dr Justin Pepperell, Dr Chris Davies, Prof. John Fleetham, Dr Mark Elliot, Dr Renata Riha, Dr Andrew Cummin, Dr Lee Dowson, Dr John White, Dr Anita Simmonds, Prof. Mary Morrell

Trial Steering Committee members Dr Ian Smith

Data monitoring committee Prof. Tim Peto, Prof. John Gibson

Advisors Prof. Peter Rothwell, Prof. Rory Collins

Research staff Barbara Winter, Rebecca Mason, Massimilliano Siccoli, Jacqui Webb, Suber Valmiki, Elizabeth Thorne, Nurit Fox, Margaret Chapman, Marjorie Vennelle, Craig Armstrong, Loiuse Spragg, Ramesh Ghiassi, Gillian Twigg, Neil Ward, Jayne Pateraki

Trial management Emma Hedley, Nicky Crosthwaite, Claire Manners, Magda Laskawiec Data management Thomas Penning, Anna Bara, Peter Stradling, Phillipa Davies, Jenny Stradling, Adam Smith, Alice Roberts

We would like to acknowledge the support of the NIHR Biomedical Research Centre, Oxford, the British Heart Foundation, London, the Oxfordshire Health Services Research Committee, Oxford and Resmed, Abingdon.

Thorax 2013;68:96. doi:10.1136/thoraxjnl-2012-202178corr1 